\title{
Duty and Distance
}

\section{Constanze Binder ${ }^{1} \cdot$ Conrad Heilmann $^{1}$}

(C) The Author(s) 2017. This article is an open access publication

\section{Introduction}

Ever since the publication of Peter Singer's article "Famine, Affluence, and Morality" has the question of whether the (geographical) distance to people in need affects our moral duties towards them been a hotly debated issue. ${ }^{1}$ Does geographical distance affect our moral duties? If so, is it of direct moral importance? Or is it of indirect importance to other aspects that affect our moral duties, such as our power to help other people?

Long after the publication of Singer's article, the relation between morality and distance has received renewed attention in contributions by many leading philosophers. ${ }^{2}$ While these contributions debate problems of duty and distance,

\footnotetext{
1 Peter Singer, "Famine, Affluence, and Morality," Philosophy and Public Affairs (Princeton University Press) 1/3 (1972): 229-243.

2 Peter Singer (1972), op. cit. See the contributions of the 2003 special issue on "Moral Distance" in The Monist 86/3, for instance: Deen K. Chatterjee, "Moral Distance: Introduction," The Monist 86/3 (2003): 327-332; Jeremy Waldron, "Who is my Neighbor?: Humanity and Proximity," The Monist 86/3 (2003):
}

We are grateful to Sine Bağatur, Martin van Hees, Sem de Maagt, Ingrid Robeyns, Willem van der Deijl as well as audiences at LMU Munich and Erasmus University Rotterdam and an anonymous referee of this journal for very helpful comments. Conrad Heilmann's work was supported by a Marie Curie Career Integration Grant from the European Union and a VENI grant from the Netherlands Organisation for Scientific Research (NWO).

Conrad Heilmann

heilmann@fwb.eur.nl

Constanze Binder

binder@fwb.eur.nl

1 Erasmus Institute for Philosophy and Economics (EIPE), Faculty of Philosophy, Erasmus University Rotterdam, 3000 DR Rotterdam, The Netherlands 
they do so by mainly focusing on duties, such as by asking what influence distance may have on duties, or whether specific kinds of distance, such as kinship distance, are vital in and of themselves in establishing duties. Often, these discussions refer to geographical distance in an offhand way, stating as obvious that it is of no moral importance. Here, we put the concept of geographical distance at the center of the analysis. We ask: what precisely is the definition and role of geographical distance in the different accounts of duties? We argue that a distinction between empirical and moral disagreement over the role of geographical distance clarifies several aspects of the debate about duty and distance. Most strikingly, several points of contention are empirical rather than moral disagreements about the role of geographical distance. This insight does not only allow us to re-assess the existing literature, but it also opens up new avenues for action and sheds light on discussion about duties towards refugees arriving at European shores, or so we argue.

Our main objective is to clarify the debate on the role of distance and moral duties by focusing on the definition and role of geographical distance. Our strategy is as follows. We first revisit and restate Singer's claim that "distance does not matter" in more precise terms in order to spell out the (often implicit) assumptions that have to hold for distance not to matter to a person's duties. This restatement allows us to distinguish between different notions of distance that can influence a person's duties to others in different ways. To be more precise, we illustrate how geographical distance can have an empirical and a moral importance for one's duties. We then show that many differences between Singer and his critics concerning distance are of empirical, rather than moral, nature. Furthermore, we provide one framework within which one can locate several hitherto unconnected discussions about duty and distance, and compare different accounts that have been put forward in either of these discussions. The perspective we advance also raises challenging new questions, for instance: what kind of (empirical) understanding of the role of distance do we base our moral claims on? We present a framework that makes clear what kinds of choices both theorists and policy makers face when confronted with this question. We delineate the space within which policy makers can influence (e.g. decrease) the impact of geographical distance on our moral duties, and show how this perspective can help in discussing policy reforms and that it sheds new light on duties in the current refugee crisis.

Footnote 2 continued

333-354; Wendy C. Hamblet, "The Geography of Goodness: Proximity’s Dilemma and The Difficulties of Moral Response to the Distant Sufferer," The Monist 86/3 (2003): 355-366; Richard Arneson, "Consequentialism vs. Special-Ties Partiality," The Monist 86/3 (2003): 382-401; Jan Narveson, "We Don't Owe Them a Thing! A Tough-minded but Soft-hearted View of Aid to the Far Away Needy," The Monist 86/3 (2003): 419-433. See also Deen K. Chatterjee (ed.), The Ethics of Assistance: Morality and the Distant Needy, Cambridge (2004): Cambridge University Press; and earlier contributions by Frances Kamm, "Does Distance Matter Morally to the Duty to Rescue?," Law and Philosophy 19 (2000): 655-681; Violetta Igneski, "Distance, Determinacy and the Duty to Aid: A Reply to Kamm," Law and Philosophy 20 (2001): 605-616; and Francesco Orsi, “Obligations of Nearness," The Journal of Value Inquiry 42 (2008): 1-21. 


\section{Singer's Distance Claim Restated}

Recent debates about duty and distance start with Singer's 1972 article. There, he offers the following radical stance: "[...] if it is in our power to prevent something very bad from happening, without thereby sacrificing anything of comparable moral importance, we ought, morally, to do it." 3 One's duty to help, Singer goes on to argue, is established independently from distance. Saving a child from drowning in a nearby pond is a duty, and so is saving a child from starving in a faraway country. That one of these children is more distant is simply not relevant in determining the respective duties in these cases. Indeed, Singer explicitly states: "[...] the principle takes [...] no account of proximity or distance." 4

In the utilitarian framework Singer employs, this claim leads to the conclusion that every person has a duty to prevent harm from (distant) others, say in case of poverty or famines, until the marginal utility of the last unit she gives up equals the marginal utility gain her sacrifice brings about. This radical stance has led to intense debates. There have been a number of critical contributions that examine Singer's general project. ${ }^{5}$ Singer himself has been expanding on his earlier work in a number of contributions, further developing the practical implications of his view, also by ultimately connecting it to the idea of philanthropy and "effective altruism." 6 Some contributions have also discussed whether distance affects one's duty to help (and if so, how) and how far-reaching those duties should be. ${ }^{7}$ In this paper, we focus on analyzing the role of the concept of distance in Singer's claim: that distance is irrelevant to discern a person's duties to (distant) others. Singer says: "I do not think I need to say much in defense of the refusal to take proximity and distance into account." 8 We disagree. Rather, claims about the (ir)relevance of distance need as much careful attention as other parts of Singer's radical stance, as attested by the discussions about distance and duties.

Let us now take a closer look at the "Distance does not matter!" slogan. Firstly, Singer is obviously referring to geographical distance in stating it. That is, he is not concerned with other kinds of distances such as emotional, kinship, temporal, cultural, linguistic, or causal distance, but rather focuses on geographical distance. ${ }^{10}$ Secondly, Singer is concerned with those features of a situation that are of direct

\footnotetext{
3 Peter Singer (1972), op. cit., p. 231.

${ }^{4}$ Peter Singer (1972), op. cit., p. 231.

5 See, for instance, Patricia Illingworth; Thomas Pogge, and Leif Wenar (eds), Giving Well: The Ethics of Philanthropy, Oxford (2010): Oxford University Press.

${ }^{6}$ Peter Singer, The Life You Can Save, Random House (2009); Peter Singer, Famine, Affluence, and Morality. Oxford (2009): Oxford University Press.

7 For a discussion of the radical stance, see for instance Deen Chatterjee (2004, op. cit.) and Rivka Weinberg, "It Ain't My World," Utilitas 21 (2009): 144-162.

8 Peter Singer (1972), op. cit., p. 232.

9 cf. the literature referred to in Footnote 2.

${ }^{10}$ Obviously, Singer's claim entails the irrelevance of other dimensions of distance, such as ties of kinship to the person in need. For a more specific discussion of these, see Peter Singer, "Outsiders: our obligations to those beyond our borders," in: D.K. Chatterjee (ed.), The Ethics of Assistance (Cambridge: Cambridge University Press, 2004), pp. 11-32.
} 
moral relevance to identify one's duties to others: it should be "in our power to prevent something very bad from happening" without us having to sacrifice "anything of comparable moral importance." 11 Of course, this leaves open the possibility that geographical distance affects our duties indirectly by, for instance, affecting our power to help. Singer shortly discusses this possibility, i.e. that being far away in geographical distance could mean that one is also (i) less effective in helping, (ii) less acquainted with people who are far away, (iii) less well informed about the situation. ${ }^{12}$ However, Singer maintains in passing that these effects are not relevant anymore in the "global village." Instant communication and direct connections made geographical distance (also indirectly) irrelevant to a person's duties.

Yet, this way to dismiss any influence of geographical distance upon one's moral duties seems a bit too quick. We need to ask how concepts like effectiveness (or power) to help and knowledge about victims can be delineated from a purely geographical understanding of distance. In order to provide an account that allows one to answer this question, we will go through three kinds of objections that Singer's claim could be subjected to and offer restatements of it that accommodate them. The first two objections deal with (i) and the third objection deals with both (ii) and (iii).

Firstly, consider the following objection against Singer's claim: if it is both the case that power to help matters and that the concept of power to help is dependent upon geographical distance, then geographical distance does matter after all. Now, it is clear that the power to do or prevent something really does matter for Singer, as it is explicitly mentioned in his radical stance that we cited earlier. It also seems plausible that in order to understand how an agent might be powerful, one needs to have an account of how an agent can make a difference across a certain geographical distance. For instance, in order to have the power to prevent a child from drowning, an agent should be able to make a difference in physically reaching that child, either by using her arms to save the child herself, or by instructing another agent or a machine, for instance. ${ }^{13} \mathrm{We}$ are not contending here that small geographical distance is required to be powerful. Rather, to be powerful in Singer's context means to be able to make a difference (across geographical distance). In and of itself, that is not an objection against Singer. It only brings an implicit assumption underlying Singers notion of power to help into the open: in his view, power is not conceptually related to geographical distance. To see why this is important, consider the following. If we would couple Singer's distance slogan with the statement "to be powerful means to be able to save everyone from drowning who is five steps or less away," then the concept of power to help hinges on a specific understanding of distance such that it becomes a contradiction to also maintain that geographical distance does not matter. As long as the understanding of how an agent might be powerful is not dependent upon geographical distance, there is no problem for

\footnotetext{
11 Peter Singer (1972), op. cit., p. 231.

12 Peter Singer (1972), op. cit., p. 231, 232.

13 Frances Kamm (op. cit.) discusses geographical distance and effectiveness in similar terms, to which we return in the next section.
} 
Singer to maintain his distance claim. Hence, in order to account for this point, Singer is required to use a concept of power in the radical stance that does not contradict the distance claim. The first part of our restatement ensures exactly that.

Singer Restated I. Geographical distance does not matter, if the concept of power to help is not derived from a specific notion of geographical distance.

Secondly, one might object that the above provision is not enough. It could still be the case that power is correlated to geographical distance, such that the latter does matter after all. That is, even if the power concept is not directly established by reference to geographical distance (such as in the example offered when discussing the first objection above), there could still be a correlation between power and geographical distance, i.e. the nearer a victim is to an agent in a geographical sense, the more powerful that agent is to help. If that were the case, then the notion of being in a position to help effectively would contradict the claim that geographical distance does not matter. The amended restatement of the claim avoids precisely this kind of problem.

Singer Restated II. Geographical distance does not matter, if the concept of power to help does not presuppose a specific notion of distance, and geographical distance and power to help are not correlated.

Thirdly, one may object that one's ability to know about the potential of something bad to happen is correlated with geographical distance. If that is true, then geographical distance matters after all. For instance, one could contend that events or circumstances that are geographically distant are harder to access epistemically than geographically near ones. The third and final restatement avoids this problem.

Singer Restated III. Geographical distance does not matter, if the concept of power to help does not presuppose a specific notion of geographical distance, geographical distance and power are not correlated, and one's ability to know about the potential of something bad to happen is not correlated with geographical distance.

The restatement does reflect (part of) the provisions that are in Singer's original article $^{14}$ : it simply combines the claim and the three provisions concerning (i) efficacy of helping, and (ii) \& (iii) knowledge about victims and their situation. We would like to stress here that the restatement exercise is merely meant to make more explicit what is already inherent in Singer's original formulation of the radical stance and the distance claim. That is, we do not mean to offer an interpretation of Singer here, but rather summarize concisely what he has to say about distance and the assumptions his radical stance is based upon. With this restatement in place, a number of misunderstandings about and objections against Singer's geographical distance claim can be avoided.

Before we discuss these in greater detail in the next section, we comment on the different ways in which geographical distance could influence one's duties, and how

${ }^{14}$ Frances Kamm, op. cit. 
they are ruled out by restatements I, II and III, respectively. Restatement I rules out a conceptual relationship between geographical distance and a variable that is of primary moral importance.

Such variables can be the power one has to help others, but it might also be one's commitments to others or one's ties of friendship. If geographical distance is conceptually linked to such a factor of primary moral importance, we take geographical distance itself to be of moral importance. Different to that, restatements II and III rule out an empirical correlation between geographical distance and morally relevant factors, such as one's effectiveness to help or the informational requirements necessary to do so. Whether geographical distance matters here cannot be decided a priori but is dependent on facts about the world. As we shall argue in the next section, much of the disagreement between Singer and his critics is ultimately concerned with such empirical questions about the relevance of distance, rather than the moral importance of distance itself.

\section{Implications of the Restatement for Debates about Morality and Distance}

Why is the restatement of Singer's claim important? There are two main reasons. For one, it makes the assumptions about the relationship between geographical distance and the morally relevant features Singer defends in his claim explicit. What is more, it helps to analyze contributions that have criticized Singer's position or seem to stand opposite to it, contending that distance matters. We now investigate in how far the restated claim sheds new light on these critical contributions.

The contributions can be divided into two broad categories: firstly, those contributions who purportedly disagree with Singer, but for which the restatement shows that the disagreement is about one or more of the implicit assumptions underlying Singer's stance, which we brought out in the restatement. Secondly, there are contributions that would demand further additions to the restated Singer claim in order to be compatible with it. We will go through each type of contribution in turn.

There are a number of accounts that can be accommodated with the restatement. The most prominent one is the article by Frances Kamm who maintains: "there are cases in which geographical distance matters." 15 However, she qualifies this by saying that it is the distance between the "extended parts" of an agent and the threat to a victim or the victim themselves that counts. She illustrates this by means of an example in which different kinds of proximity and distance play a key role: "Suppose I stand in a part of France, but I have very long arms that reach all the way to the other part of France, [...] allowing me to reach a child drowning in a pond at a distance [...]. Intuitively, I think this case is treated as one where the child is near." 16

\footnotetext{
15 Frances Kamm, op. cit.

${ }^{16}$ Frances Kamm, op. cit., p. 662, emphasis in the original.
} 
In this example (and other examples that she discusses in her article, in similar vein), she is not referring to pure geographical distance, but rather to an account in which the ability or power to help is correlated with geographical distance. Furthermore, Kamm discusses examples in which she alludes, albeit indirectly, to epistemic and emotional factors that can be correlated to geographical distance. ${ }^{17}$ Hence, in light of the previous discussions, we maintain that Kamm's position seems to be mainly in conflict with the idea, expressed in the second restatement of Singer's distance claim, that power is not to be correlated with geographical distance.

This nuance in the disagreement between Kamm and Singer is crucial. Indeed, the disagreement is an empirical one rather than a moral one. Both of them agree that geographical distance does not matter itself for establishing duties. However, they disagree about whether variables that are of primary moral importance, such as the ability or power to help, can be disentangled from geographical distance or not. Singer explicitly says that geographical distance does not affect our power to avoid something bad from happening in the modern world. ${ }^{18}$ Kamm discusses cases in which geographical distance can affect one's power to intervene. ${ }^{19}$ That, however, is an empirical (rather than moral) disagreement between Singer and Kamm, about whether the conditions of the restated distance claim hold: are power and geographical distance correlated or not? Depending on how we sort out this empirical question decides upon whether Kamm's and Singer's position are reconcilable or not: there is no moral disagreement between these two authors. They agree that geographical distance as such is not of primary moral importance. What they disagree about is an empirical question, namely whether we live in a world in which geographical distance does affect parameters that are of moral importance, such as our power to help others.

It could be argued that Singer's distance claim is rather heroic empirically: power to rescue and the ability to know about rescuing seem to be closely correlated to geographical distance in the majority of cases. While it is also relatively easy to find examples in which they are not, it seems that by and large geographical distance to the victim is often either correlated or at least a good indicator of how much power and knowledge an agent may have to intervene. ${ }^{20}$ One can agree with Singer that the correlation between one's power to avoid something bad from happening and geographical distance decreased with the globalized world moving closer together in the recent decades. However, the question whether this correlation has ceased to exist and thus that geographical distance is (empirically) irrelevant for one's power to help can be questioned, as Kamm did. As we will discuss below, it is within the scope of public policy, however, to further decrease the importance of geographical distance for one's ability to help, bringing our actual world closer to the world in which Singer's radical stance that geographical distance does not matter at all holds true. We will pick up this question once again in sections 4 and 5.

\footnotetext{
17 Frances Kamm, op. cit., p. 663f.

18 Peter Singer (1972), op. cit.

19 Frances Kamm, op. cit.

${ }^{20}$ Violetta Igneski (op. cit.) demonstrates this in detail.
} 
A second type of criticism against Singer's distance claim goes beyond aspects that can be dealt within the restatement. Rather, this second type of criticism can only be dealt with when adding further conditions to the restatement. We see this as an advantage of the methodology adopted in this paper: the restatement simply reflects a summary of Singer's views on distance, while at the same time serving as a baseline position that can be criticized or expanded upon and thereby allows making the differences between Singer and his critics more explicit.

Additions to the restatement come in the form of providing arguments for the moral relevance of other variables, which often can be expressed as the relevance of other notions of distance. For example, Miller argues that co-nationals have special duties towards each other. ${ }^{21}$ That is, he maintains that there is an important sense in which citizens of the same country are less distant to each other and that this is morally relevant. Unger argues a similar point by employing the concept of psychological (or emotional) distance. ${ }^{22}$ Likewise, Arneson, as well as Reader conceptualize special ties and relationships in this way. ${ }^{23}$ In order to accommodate these kinds of positions about how different kinds of distance can be morally relevant, they could be added to the restatement of Singer. That is, if any of the above authors would like to endorse Singer's claim about the irrelevance of geographical distance, they would need to uphold that the respective dimension of distance for which they claim moral importance, such as citizenship, psychological or emotional distance, is not conceptually related or empirically correlated to geographical distance. The restatement would need to be further amended to reflect such a position.

Crucially, the above debates (and possible additions to the restatement that they might imply) are of a different type than the ones discussed before. The disagreement here lies in whether the different kinds of distance that are evoked by the authors, such as kinship distance, are of direct moral importance in establishing one's duties. As such, the additional conditions to the restatement the above positions would require (for geographical distance not to matter) are considerably stronger: not only are such kinds of distances required to be of direct moral importance in establishing one's duties, but they are also required not to be constitutive of or correlated to geographical distance. If one defends a pronounced view on how a specific kind of distance is of direct moral importance in establishing one's duties, it is not straightforward whether and how Singer's stance about the irrelevance of geographical distance can be maintained. In section 5, we will discuss one such case where proximity of refugees can establish a specific duty towards them.

What is the upshot of this discussion regarding the restatement of Singer and the debates about distance and duty? It seems to us that both Singer and other commentators underestimate the fact that geographical distance can be related in various ways to factors that are morally relevant in discerning one's duties to others.

\footnotetext{
${ }^{21}$ David Miller, “The Ethical Significance of Nationality,” Ethics 98 (1988): 647-662.

${ }^{22}$ Peter Unger, Living High and Letting Die: Our Illusion of Innocence, (New York: Oxford University Press, 1996).

${ }^{23}$ See Richard Arneson (op. cit.) and Soran Reader, "Distance, Relationship and Moral Obligation," The Monist 86/3 (2003): 367-381.
} 
These factors can be of primary moral importance, as those explicitly stated by Singer, like the power one has to avoid something bad from happening. Alternatively, such morally relevant factors can be other dimensions of distance, such as cognitive or epistemic distance, for instance. Even though there seems to be broad agreement between Singer and his critics that geographical distance should not be of direct moral relevance to one's duties, they disagree about the (empirical) relationship between geographical distance and those factors that are of direct moral importance to establish one's duties to others. ${ }^{24}$

Apart from clarifying the debate and identifying the precise points of disagreement between the various camps of the debate, the insights generated here have also implications for how policy can (and possibly should) affect people's duties towards each other by influencing the empirical relationship between geographical distance and morally relevant parameters. We now turn to these implications.

\section{Implications of the Restatement for Public Policy}

As argued in the previous section, much of the debate about the importance of geographical distance is about an empirical question: are those factors that are of direct moral relevance to one's duties correlated to geographical distance? Singer claims that even though this might have been the case in earlier times, this correlation does not hold in a globalized world. Others hold that the correlation is still there to such an extent that it can result in a decrease of one's moral duties to distant others.

Irrespective of the stance one takes in this debate, the point both sides seem to agree upon is that technological and other developments can decrease the influence of geographical distance on morally relevant factors, such as one's power to avoid something bad from happening in a geographically distant place. This insight allows us to see existing practices in international organizations from a new perspective and furthermore to identify future policies that reduce the diminishing effect of geographical distance on one's duties.

First, it allows us to see some of the prevailing and current trends in development and aid of the poor in new light. Consider for instance the widespread practice by development organizations (such as Worldvision, Save the Children, and UNICEF) to offer potential donors to be a sponsor to a child. Clearly, on the account developed here, we can characterize this practice as a way to disentangle geographical distance between Western donors and children in Africa and Asia from variables that are morally relevant to establish our duty, such as knowledge about the help needed ${ }^{25}$ : while the children that can be sponsored are geographically

\footnotetext{
24 Indeed, Violetta Igneski (op. cit.) holds that geographical distance is a (empirically relevant) proxy for morally relevant aspects.

25 Note that this question as to how policy can influence a person's moral duty to those who live far away is different from the question how policy can influence a person's willingness to comply with those duties. The later question entered the debate as to whether Singer's radical stance is overly demanding. The field of moral psychology revealed important insights about the tension between the common acceptance that "geographical distance should not matter" versus the intuition that most people care more about what is less distant to them on a variety of dimensions, such as emotion, kinship, culture, language,
} 
distant, they are brought closer to potential sponsors in other ways. That is, these measures presuppose that with geographical distance, there is inferior knowledge about help needed, and are designed to overcome it. Other measures, such as appeals to donate for the victims of natural disasters, can be characterized in similar fashion.

Second, the insight that a crucial question is an empirical rather than a moral one opens up new challenges for policy making. (How) is it possible to reduce the dependence of morally relevant factors (such as the power to intervene) on the geographical distance between the people in need and the (potential) duty bearer?

As Singer pointed out, much has changed in recent years due to technological development that allows one to get information about most parts of the world in an instant and take immediate and effective action. Nevertheless, even though one's possibilities to inform oneself and the effectiveness of taking action around the globe increased in the last decades, many would argue that geographical distance is still negatively affecting one's power to intervene. However, there is scope for future policies to change this. For example, information about places where support is needed in the world could be spread much more systematically. Similarly, one's power to intervene over a distance could be further increased by establishing respective networks even before the help is in fact required.

As we write this article, in 2016, there are many migrants from countries in the Middle East and Africa who have come to Europe, seeking refuge, asylum, or opportunity. Given the numbers of migrants concerned, especially the numbers of those seeking asylum, and given how the situation unfolded in the years of 2015 and 2016, the current situation can be described as Europe's largest refugee crisis post WWII. Singer's article was also written under the impression of a refugee crisis, but one that occurred in geographical distance to Western countries. ${ }^{26}$ This time, the situation is different: refugees and other migrants have all but nullified the geographical distance to Western countries, either by arriving in Western countries, or in countries that are geographically close to them.

The current refugee crisis in Europe clearly presents a humanitarian and political challenge to the European Union, as well as a moral challenge to all European citizens. Long-distance migration to Europe is very risky and puts the life of those who undertake it in danger, and many migrants suffer and die while migrating. In terms of the discussion of geographical distance and its relation to moral duties, the most striking feature of the crisis is that it presents a crucial twist on the kinds of examples and situations that Singer considers ${ }^{27}$ : those who have been distant people in need to Europeans only a few months ago are now geographically close to them. Does this reduction in geographical distance affect the duty of European citizens towards them?

\footnotetext{
Footnote 25 continued

or history. See among others, Judith Lichtenberg, "Absence and the unfond heart: why people are less giving than they might be," in: D.K. Chatterjee (ed.), The Ethics of Assistance (Cambridge: Cambridge University Press, 2004), pp. 75-97.

26 Peter Singer (1972), op. cit.

27 Peter Singer (1972), op. cit.
} 
One way to interpret the situation is that strangers in need have taken action to minimize the geographical distance between them and those who can help, in order to overcome the kinds of relations between geographical distance and the power to help that we have discussed earlier in the restatements of Singer's position. In particular, minimizing geographical distance means that those who can help do not face obstacles to use their power to help, in case that power to help is derived from geographical distance (Singer Restated I) or correlated with it (Singer Restated II). Moreover, in case either one of the aforementioned holds, minimizing geographical distance also means that the ability to know for someone who has the power to help is increased, in case that ability is correlated with geographical distance (Singer Restated III). In a word, a migrant who comes to Europe to seek asylum thus overcomes geographical distance to those who can help, says: "I am helping you help me", to reverse a popular dictum.

Yet, can it really be said that the reduction of the geographical distance affects the information people have about the situation of refugees and their ability to help them? It does not seem self-evident that the reduced geographical distance does indeed come with an increase in knowledge about the need to help or the power to help: information about the difficult and life threatening situation of Syrians and Iraqis could have been obtained while they were still in their home countries or in refugee camps in Turkey or Lebanon. Similarly, in today's interconnected world it is relatively easy to support people in such circumstances, either institutionally by supporting UNHRC, for instance, or individually, via NGOs. The information about and effective power to help is not necessarily increasing due to the reduction of geographical distance: there is very little information in the media, for instance, about the situation in some of the main refugee camps in Europe, such as Calais in France. In short, there are reasons to question that geographical distance is strongly correlated with the two variables of primary moral importance (according to Singer) and thus whether the reduction in geographical distance of refugees coming to Europe does indeed affect the moral duties of European citizens towards them along Singer's account. ${ }^{28}$

While the analysis presented here highlights how our argument can be applied in practice and how it sheds new light on the refugee crisis and its moral implications, the observations made so far also highlight one of the main points made in this paper: whether refugees coming to Europe and whether the reduction in geographical distance between them and European citizens would indeed lead to a change in duty towards them along Singer's account, is an empirical question. Its answer depends on the actual empirical relationship between the two variables of primary moral importance for duties according to Singer, i.e. the knowledge about the need for help and the power to help, and geographical distance. ${ }^{29}$ However, could there be other morally salient variables, such as being at the border of a country, that are dependent on geographical distance or a specific geographical

\footnotetext{
${ }^{28}$ Note that settling the question about the relationship between geographical distance and the knowledge about the need for help, as well the power to help is an empirical matter, as demonstrated earlier in the paper. The claims in this paragraph are thus open to empirically informed debate.

29 Peter Singer (1972), op. cit.
} 
position, and strongly affect the kind of duty citizens of this country have towards the people seeking help? We now turn to this question.

\section{Distance and Duty of Europe towards Refugees}

The reduction of geographical distance due to refugees moving from war-torn countries towards or across the borders of Western states can have a more fundamental impact on the duties Western countries have towards them: as Miller argues, the new geographical proximity, that is, refugees arriving at the border of a country, can establish an immediate duty of care of the respective state. ${ }^{30}$ In this case, geographical proximity turns a general duty into a specific duty: when people in Syria are threatened by violence and famines, then (according to Singer) in principle all citizens of the world, who know about it and in whose power it is to help, have a duty to help them. In this case, however, there is no duty of a specific group of people or a specific state, say the Netherlands, to discharge the duty to a specific Syrian citizen. However, once people stand at the borders of a state, or cross it, it can be argued that this new geographical proximity imposes an immediate duty of care upon the respective state, or that their presence and new geographical location triggers new obligations towards them. ${ }^{31}$

Thus, there can be other morally salient variables, such as being at the border of a country, that are correlated with geographical distance and strongly affect the kind of duty citizens of this country have towards the people seeking help. One could thus say that the refugees traveling to Europe influence another morally salient variable $^{32}$ : by reaching and crossing the borders of a Western country, they ground a specific duty the respective state (or European Union) has to them due to their new geographical location. However, what makes a person being at the border of a country a morally relevant factor? Miller argues that a specific obligation is created on the side of the approached state due to the geographical location of a person in need of assistance, more specifically her physical proximity and the state's (unique) capacity to assist. ${ }^{33}$ This physical proximity and the state's capacity to assist creates a vulnerability of the person in need of assistance in case the state that is in a unique

\footnotetext{
30 See p. 394 in David Miller, "Justice in Immigration," European Journal of Political Theory 14 (2015): 391-408.

31 See David Miller (2015, op. cit.); Paulina O. Espejo, “Taking Place Seriously: Territorial Presence and the Rights of Immigrants," The Journal of Political Philosophy 24 (2016): 67-87; Robert E. Goodin, "What is So Special about Our Fellow Countrymen?," Ethics 98 (1988): 663-686; and Jaako Kuosmanen, "Perfecting Imperfect Duties: The Institutionalisation of a Universal Right to Asylum," Journal of Political Philosophy 21/1 (2013): 24-43. Note that David Miller (2015, op. cit.) does not use the terminology of specific and general duties. For a more detailed discussion of specific and general duties, see Robert Goodin (op. cit.). For a defense of a universal right to asylum and a discussion of a variety of policy schemes that discharge the corresponding duties of states, see Jaako Kuosmanen (op. cit.).

32 See David Miller (2015, op. cit.), and Paulina Espejo (op. cit.) for a more detailed discussion of this claim.

33 David Miller (2015), (2015, op. cit.); David Miller, Strangers in Our Midst, The Political Philosophy of Immigration, (Cambridge (MA): Harvard University Press, 2016).
} 
position to help does not allow them to enter. If a refusal of a state to admit refugees at its borders can cause severe harm to them, say by exposing the person to danger at sea, then this unique power to help (or refuse to help), creates the specific duty. ${ }^{34}$

Upon closer inspection, it turns out that the role of geographical location or proximity for this specific obligation of one state towards people in need of assistance is also due to the relationship between the geographical location and a morally salient variable, i.e. its unique power to assist in this case, but not due to the moral relevance of geographical distance itself. In this case it is a conceptual relationship between distance and power to help (Singer Restated I): the unique power to help is conceptually linked to the concept of a nation state, its territorial sovereignty and the geographic location of a person in need of assistance in case she is at the state's borders or has crossed it.

It is important to point out that our argument does not rely on the endorsement of this specific duty defended by Miller. What we aim to show is that even in this case the importance of geographical location can be traced back to its relation to another morally salient factor, namely a state's (unique) capacity to help. Having made this explicit, one can see that objections against Miller's argument appear in a new light.

A possible objection to Miller's claim is that geographical distance does not give countries a duty that isn't had by others. ${ }^{35}$ At first sight, it does seem dubious to claim, for instance, that Lebanon has duties towards Syrian refugees that the United States does not have, due to its geographical location. Similarly, claims that Greece, Italy, or Spain have more extensive duties towards refugees arriving at their shores than other European countries, like Germany or the Netherlands, is a hotly debated and contested claim. At closer inspection, however, it turns out that this criticism is again one about the relationship between geographical location and proximity and a state's (unique) power to help. In the case of Lebanon, many might agree that its geographical location puts it into a unique position to help refugees fleeing on land to neighboring countries. Lebanon has a power to assist that other countries, such as the United States, do not have, namely to allow them to cross its borders into safety (unless of course refugees would/could flee directly from Syria to the United States or other states in greater geographical distance). However, beyond this immediate act of admittance it seems questionable whether Lebanon has unique or even greater power to help due to its geographic location. Other states, such as the United States or European ones, might be much more powerful to help in terms of their economic capacities, for instance. This becomes even more apparent in cases in which the unwillingness of other states to admit refugees leads countries like Lebanon to a situation in which its power to help itself is at risk, due to the greater number of people it needs to assist in the light of the unwillingness of other states to assist as well. $^{36}$

\footnotetext{
${ }^{34}$ Note that David Miller (2016, op. cit., p. 84) does not discuss the reasons for these specific obligations created by refugees' vulnerability in detail. The role of vulnerability in the text is our rendition of his argument.

${ }^{35} \mathrm{We}$ are grateful to an anonymous referee for raising this objection.

${ }^{36}$ According to the UNHCR, there were more than 1 Million Syrian refugees registered in Lebanon per mid-2016, which is more than one fifth of their total number. See also: http://data.unher.org/ syrianrefugees/country.php?id=122 (Accessed: October 12, 2016).
} 
Again, the root of the discussion as to whether geographical proximity creates special obligations (of Lebanon in this case), is not a case of geographical proximity itself relevant or irrelevant for a state's duties, but rather in how far the geographical position of a state is linked to its (possibly unique) power to help. Once this relationship is disentangled and spelled out clearly, it becomes clear that the unique power to help of neighboring countries, such as Lebanon, is due to their unique position to open their borders to refugees and provide them first shelter. The overall power to help, however, goes well beyond the admittance of people at a state's border to safe ground. Among others, it is crucially influenced by a state's economic power, a factor that is irrespective of geographical distance and creates obligations for countries economically more powerful than Lebanon, irrespective of their geographical distance. ${ }^{37}$

In the case of Greece and the European Union, the link between geographical location, a country's power to help, and its special obligations towards people in need of assistance arriving at its borders becomes even weaker. Not only are there many countries within and outside the European Union (such as Germany, the Netherlands for instance), that are economically in a more powerful position to help, but even the (unique) power of Greece to decide about admittance of the people that arrive at its shore, is less straightforward/strong than in the case of Lebanon. In light of the joint border control of the Schengen area of the European Union, the unique power of Greece to admit people at its borders or at least to guide them to safe places in order to avoid immediate harm to them can be taken as a joint responsibility of all states of the European Union. Furthermore, one can see people arriving at the shores of Greek islands as asking for shelter in Europe (rather than Greece) and thus it seems difficult to sustain any special obligation of Greece due to its geographical location due to it not having the unique power to admit refugees at its borders (or not). Thus again the duty is not per se due to the geographical position of a state vis-à-vis the arriving refugees, but rather due to the relationship between this geographical proximity and its power to help. Greece's power to help is not only limited economically, but also crucially influenced by the joint European decisions about the control of Europe's (and thus also Greece's) borders. Once one shifts the focus from geographical position towards a state's power to help people in need, it seems at least questionable whether the bearer of these (specific) duties is the respective nation state where refugees arrive, such as Greece, or the entire European Union.

The discussion of the current refugee crisis and the specific duties that states have towards refugees due to their geographical location/proximity, illustrates the more general point made in the previous sections: even in theories (such as Miller's), that allow for more extensive duties towards people in need of assistance that are inside or at the borders of a state's territory, it is not geographical location per se that matters, but the correlation between geographical proximity and (a possibly unique)

\footnotetext{
37 It is important to note that there can be other important factors that influence a state's duty to assist, such as its responsibility in creating the situation for refugees to flee their country. Due to the topic of this article, we restrict our discussion to the role of morally relevant factors that are correlated to geographical proximity.
} 
position to help, that creates the specific duty of a state to help refugees arriving at its borders.

\section{Conclusions}

We have pointed to two different ways in which geographical distance can matter to a person's duties: it can be of direct moral importance or it can be relevant due to a correlation between some morally relevant factor and geographical distance. To illustrate this distinction, we offered a restatement of Singer's slogan that "distance does not matter" to make explicit the qualifications he offered with regards to the role of geographical distance for establishing duties in his 1972 paper. We used the restatement to deflate debates about the role of distance by showing that they do not reflect moral, but rather empirical, disagreement between Singer and his critics. The insight that the fundamental disagreement is of an empirical nature opens up new ways in which to think about duties in our globalized world and new questions in how far the relevance of geographical distance to one's duties should/can be reduced by individual and public action. The analysis sheds new light on the duties towards refugees currently coming to Europe and points to new possibilities for public policy making for further disentangling geographical distance from morally relevant factors and thus move closer to the global moral village Singer had in mind when making his claim that geographical distance does not matter.

Open Access This article is distributed under the terms of the Creative Commons Attribution 4.0 International License (http://creativecommons.org/licenses/by/4.0/), which permits unrestricted use, distribution, and reproduction in any medium, provided you give appropriate credit to the original author(s) and the source, provide a link to the Creative Commons license, and indicate if changes were made. 